\title{
Anti-Biofilm Action of Biological Silver Nanoparticles Produced by Aspergillus tubingensis and Antimicrobial Activity of Fabrics Carrying it
}

\author{
Alexandre Gomes Rodrigues ${ }^{1(\mathbb{D})}$, Rita de Cássia Ruiz ${ }^{2}{ }^{\mathbb{D}}$, Priscila J. R. G. Selari ${ }^{3}{ }^{(\mathbb{D}}$, Welington Luiz de \\ Araújo 4(D), Ana Olívia de Souza ${ }^{1, *(D)}$ \\ 1 Development and Innovation Laboratory, Instituto Butantan, Avenida Vital Brasil, 1500, Zip Code 05503-900, São Paulo, \\ SP, Brazil; alexgrpharmazie@gmail.com (A.G.R.); ana.souza@butantan.gov.br (A.O.S.); \\ 2 Bacteriology Laboratory, Instituto Butantan, Avenida Vital Brasil, 1500, Zip Code 05503-900, São Paulo, SP, Brazil; \\ rita.ruiz@butantan.gov.br (R.C.R.); \\ 3 Federal Institute of Education, Science and Technology Goiano. Rodovia GO-154, Km 03, Zip Code 76300-000, Ceres, \\ GO, Brazil; priselari@gmail.com (P.J.R.G.S.); \\ 4 LABMEM, Microbiology Department, ICB II, Avenida Professor Lineu Prestes, 1374, Universidade de São Paulo, Zipe \\ Code 05508-900, São Paulo, SP, Brazil; wlaraujo@usp.br (W.L.A.); \\ * Correspondence: ana.souza@butantan.gov.br (A.O.S.);
}

Received: 11.02.2021; Revised: 15.03.2021; Accepted: 20.03.2021; Published: 31.03.2021

Abstract: Biological silver nanoparticles (AgNPs) were synthesized using the marine endophytic fungus Aspergillus tubingensis and inhibited Bacillus subtilis biofilm formation at low concentrations. Cotton and polyester fabrics impregnated with AgNPs were analyzed by transmission electron microscopy (TEM), and the concentration of AgNPs in both fabrics was determined using inductivelycoupled plasma atomic emission spectrometry (ICP-AES). The fabrics carrying the AgNPs inhibited the Staphylococcus aureus and Escherichia coli growth by 100\%. Both fabrics impregnated one time with AgNPs inhibited yeasts' clinical species' growth, Candida albicans, Candida glabrata, and Candida parapsilosis, from $80.1 \%$ to approximately $98.0 \%$. Besides the anti-biofilm effect, the AgNPs impregnation process on cotton and polyester fabrics was highly efficient, and both fabrics presented antimicrobial effects against clinically relevant bacteria and yeast species. The results evidence that functionalized textiles containing these biological AgNPs can play an essential role in combating pathogenic microorganisms. Thereby offering an alternative to design effective solutions, mainly for hospital garments and biomedical devices, to avoid microorganisms transmissions and hospitalacquired nosocomial infections.

Keywords: Bacillus subtilis; anti-biofilm; Candida sp.; antimicrobial activity; fabrics.

(C) 2021 by the authors. This article is an open-access article distributed under the terms and conditions of the Creative Commons Attribution (CC BY) license (https://creativecommons.org/licenses/by/4.0/).

\section{Introduction}

Antimicrobial resistance has threatened the lives of a considered number of hospitalized patients worldwide [1]. Metallic nanoparticles (MNPs) possess invaluable applications across different sectors, and the application of silver nanoparticles (AgNPs), in particular, has proved to be advantageous due to their antimicrobial activity against several clinically relevant pathogens [2]. As part of the effort to combat hospital-acquired infections, a high priority topic nowadays, functional materials able to inhibit pathogens' growth are very relevant [3, 4].

While researchers have produced large knowledge about the synthesis of nanomaterials employing physical [5] and chemical [6] methods, high energy costs and the use of chemical 
reagents in these conventional methods is a serious problem with high environmental impact [7]. Consequently, biological approaches provide a significant advantage as a means to obtain MNP. There are several options of eco-friendly methods to synthesize nanoparticles, and plants [8] and microorganisms $[9,10]$ have been the main source of bioactive molecules that can synthesize MNP through metal bioreduction, thereby decreasing their toxicity and bioavailability [11]. Although the synthesis of MNP using bacterial bioactive molecules is prevalent, fungi present numerous advantages related to the process and production of MNP.

Recently, there has been a significant increase in the number of studies of biological MNPs. However, despite our group's scientific contributions concerning the use of Aspergillus tubingensis to synthesize AgNPs, these nanoparticles' effects have not been comprehensively investigated to date.

Previously, we have demonstrated that AgNPs efficiently inhibit Gram-positive and Gram-negative bacteria when impregnated on fabrics at low concentrations [9].

The current study is describing the biosynthesis of AgNPs using the fungus $A$. tubingensis followed by the evaluation of cotton and polyester fabrics carrying these AgNPs. Moreover, this study brings new information through the evaluation of the bacterial biofilm inhibition and the fabrics' antimicrobial activity. The application of biological AgNPs, synthesized by $A$. tubingensis, with antibacterial and antifungal activity in textiles is an attractive purpose that can be explored for hospital garments to avoid microorganisms transmissions and hospital infections.

\section{Materials and Methods}

\subsection{Fungus morphology analysis by scanning electron microscopy (SEM).}

The fungus A. tubingensis was previously isolated from Rizhophora mangle following the method previously described [12] and deposited at the Oswaldo Cruz Institute Collection (IOC, Rio de Janeiro, RJ, Brazil) and at the Collection of Microorganisms for Biocontrol of Plant, Pathogens and Weeds from "Embrapa Recursos Genéticos e Biotecnologia (CENARGEN, Brasília, DF, Brazil)" under the number IOC 4684 and CEN1066, respectively. After the growth in potato dextrose agar (PDA), the fungus was fixed with a modified Karnovsky solution (paraformaldehyde at $2.5 \%$ and glutaraldehyde at $2.5 \%$ in $0.1 \mathrm{M}$ cacodylate buffer ( $\mathrm{pH}$ 7.2)) and $\mathrm{CaCl}_{2} 0.001 \mathrm{M}$ [13]. After the fixation, the cells were washed thrice with the same buffer for $15 \mathrm{~min}$ and dehydrated in a graded series of acetone $(15 \%, 30 \%$, $50 \%, 75 \%, 95 \%, 100 \%$ ) for $15 \mathrm{~min}$. The last step was repeated three times, and after that, the sample was subjected to critical point drying with $\mathrm{CO}_{2}$ (Leica CPD 030). Samples were covered with a gold film (in Sputter EMITEC for 4 min under $25 \mathrm{~mA}$ ) and examined by SEM (LEO Gemini 982, SEM at an accelerating voltage of $10 \mathrm{kV}$ ). Images were acquired by secondary electron analysis and analyzed concerning modifications or ultrastructure arrangements in the cell morphology.

\subsection{Silver nanoparticles biosynthesis.}

The A. tubingensis fungus was grown in PDA at $28{ }^{\circ} \mathrm{C}$ for a week and used for the AgNPs biosynthesis, as previously reported [2]. The AgNPs biosynthesis was monitored using UV-VIS spectrophotometer (Agilent 8453) from 200 until $800 \mathrm{~nm}$ during $96 \mathrm{~h}$, and the AgNPs were characterized using transmission electron microscopy (TEM), average diameter size 
determination, size distribution, and zeta potential by photon correlation spectroscopy NanoSizer (Malvern Instruments Corp., Worcestershire, UK) [2].

\subsection{Impregnation of silver nanoparticles on cotton and polyester fabrics by the Padding} method.

To impregnate the AgNPs on cotton and polyester fabrics, the material was first washed, sterilized in an autoclave, and dried at room temperature (RT). Fabrics measuring 10 $\mathrm{cm}^{2}$ were immersed into $10 \mathrm{~mL}$ of AgNPs dispersion until complete wetting and subsequently compressed between two rolling pins, using a rolling machine (Marcato, Padova, Italy). The fabrics were impregnated with AgNPs one, two, and four times and dried at RT protected from light for $24 \mathrm{~h}$.

\subsection{Concentration of silver in the AgNPs and on the impregnated cotton and polyester fabrics.}

The silver concentration in the nanoparticles and on the impregnated fabrics was determined by inductively coupled plasma atomic emission spectrometry (ICP OES5100 VDV, Agilent Technologies, Tokyo, Japan) by comparison with a standard calibration curve prepared with silver, as previously reported [9].

\subsection{Analysis of cotton and polyester fabrics morphology by SEM.}

The morphology of the cotton and polyester fabrics with and without the AgNPs incorporation was analyzed using SEM and images were acquired (JEOL JSM - T300 microscopy, Tokyo, Japan) at $20 \mathrm{kV}$ with secondary electron detectors. Samples were prepared using aluminum support (stubs) covered with a double-sided tape recovered with gold by 100 s. Images were recorded by a Proscan high-speed slow-scan CCD camera and processed in the Analysis 3.0 system.

\subsection{Antimicrobial activity of fabrics carrying silver nanoparticles.}

The antimicrobial activity assays were performed as previously reported [9]. To determine the antibacterial activity, the cotton and polyester fabrics $\left(1 \mathrm{~cm}^{2}\right)$ carrying the AgNPs were incubated with suspensions of a mid-logarithmic phase culture of Escherichia coli (ATCC 25922) or Staphylococcus aureus (ATCC 25923) in a poor-broth nutrient medium (1\% bactotryptone and $0.5 \%(\mathrm{w} / \mathrm{v}) \mathrm{NaCl})$ in the concentration of $1 \times 10^{5} \mathrm{CFU} / \mathrm{mL}$. Cultures were carried out in triplicate at $30{ }^{\circ} \mathrm{C}$ and $150 \mathrm{rpm}$, and the bacterial growth was determined after $24 \mathrm{~h}$ by the absorbance of the suspensions at $595 \mathrm{~nm}$. Gentamicin at 8 and $16 \mu \mathrm{g} / \mathrm{mL}(17.0-34.0 \mu \mathrm{M})$ was used as a positive control, and untreated bacteria were used as the negative control. The percentage of bacterial growth inhibition was calculated by comparison with the negative control.

To evaluate the antifungal activity, fragments of the fabrics $\left(1 \mathrm{~cm}^{2}\right)$ were placed in glass tubes with $0.8 \mathrm{~mL}$ of distilled sterile water and mixed for $10 \mathrm{~min}$ in a rotary stirrer (Labnet 211DS, Edison, New Jersey, USA) at $220 \mathrm{rpm}$. Each sample received $2.2 \mathrm{~mL}$ of potato dextrose (PD) broth and was incubated with $10 \mu \mathrm{L}$ of a suspension of Candida albicans (ATCC 36802), Candida glabrata (IOC 4565), or Candida parapsilosis (IOC 4564) at $1.87 \times 10^{5} \mathrm{CFU} / \mathrm{mL}$ (prepared according to a standard curve previously established in our laboratory), at $32-35^{\circ} \mathrm{C}$ and $220 \mathrm{rpm}$ for $24 \mathrm{~h}$. After incubation, $10 \mu \mathrm{L}$ of each suspension was serially diluted, and 
each dilution was incubated in a dish plate containing PDA at $32{ }^{\circ} \mathrm{C}$ for at least $48 \mathrm{~h}$. The score of CFU/mL was counted and calculated by comparing it against the negative control.

The pathogens $C$. glabrata (IOC 4565) and C. parapsilosis (IOC 4564) are clinically isolated strains from the Microbiology Department at Sao Paulo Federal University (Sao Paulo, Brazil) deposited at the Oswaldo Cruz Institute Collection (IOC, Rio de Janeiro, RJ, Brazil).

\subsection{Anti-biofilm action of silver nanoparticles - analysis by SEM.}

The bacterium Bacillus subtilis was cultivated on Müller-Hinton agar at $37{ }^{\circ} \mathrm{C}$, and a suspension in PBS (pH 7.2), with an optical density of 1.0 at $600 \mathrm{~nm}$, was prepared. To analyze the biofilm formation, $2 \mathrm{~mL}$ of this suspension was added to each well of a 12 well microplate containing sterile coverslips of $13 \mathrm{~mm}$ diameter in each well. Each well was treated with 10 $\mu \mathrm{L}$ of $\mathrm{AgNO}_{3}$ or diluted $\mathrm{AgNPs}$, resulting in final concentrations of 8, 16, and $32 \mu \mathrm{M}$, and the plate was incubated at $28{ }^{\circ} \mathrm{C}$ at $150 \mathrm{rpm}$ for $24 \mathrm{~h}$. Controls were performed with untreated bacterial cells, or bacterial cells treated with streptomycin/penicillin $(2,500 \mathrm{UI} / \mathrm{mL} / 2.5$ $\mathrm{mg} / \mathrm{mL})$.

For the SEM, the B. subtilis was treated with $0.01,0.1,1,10$, and $50 \mu \mathrm{M}$ of AgNPs or $\mathrm{AgNO}_{3}$ as control. Samples were fixed and processed as described above and were dehydrated in a graded series of ethanol solution (30-100\%). The critical point drying was performed with $\mathrm{CO}_{2}$ in a CPD 030 equipment (Leica Microsystems, Heerbrugg, Switzerland), and samples were covered with a gold film and observed using SEM (FEI QUANTA 250 SEM, Netherlands) and accelerating voltage of $10 \mathrm{kV}$. Images were obtained by secondary electron analysis [14] and analyzed considering modifications or ultrastructure arrangements on the cell morphology.

\section{Results and Discussion}

\subsection{A. tubingensis morphology by SEM.}

Although the fungus $A$. tubingensis strain had been previously identified by molecular analysis [2], in this study, we are showing its morphology by SEM (Figure 1). The fungus isolates proliferated rapidly on PDA. The colonies were white initially, turned greyish, and finally black within 3-4 days. Conidiophores and conidia were present in a high amount, and there was high sporulation. The morphological characteristics are according to Aspergillus sp. previous identification [15].

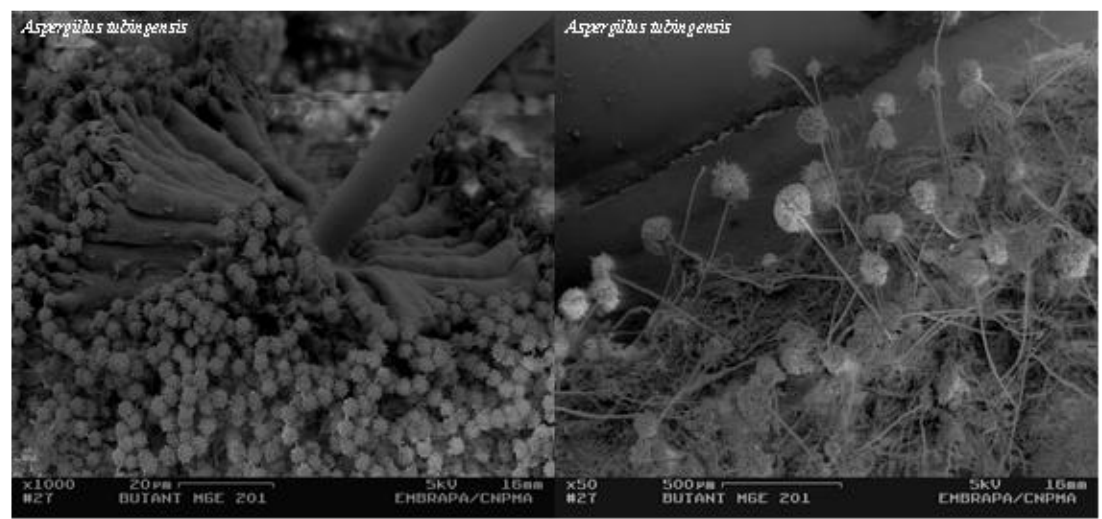

Figure 1. Scanning electron microscopy of A. tubingensis (IOC 4684 / CEN1066). Samples were covered with a gold film and examined with an FEI QUANTA 250 SEM, an accelerating voltage of $5 \mathrm{kV}$. Bars are at $16 \mu \mathrm{m}$. 
3.2. Silver nanoparticle formation, the concentration of silver in it, and in the impregnated cotton and polyester fabrics.

The formation of AgNPs was monitored by UV-Vis spectroscopy for at least $96 \mathrm{~h}$. The brownish color formation, together with the surface plasmon resonance (SPR) band around 420-430 nm was observed and is evidence of AgNPs formation. Nanoparticles size observed employing TEM was $35 \pm 10 \mathrm{~nm}$, uniform and equitably distributed, as first reported [2] (data not showed).

The silver concentration present in the AgNPs determined by ICP OES was $93 \pm 23$ $\mathrm{mg}$, corresponding to $86.2 \pm 21.3 \%$ of the theoretical value $(107.9 \mathrm{mg})$. This data is related to the fungal filtrate reaction's efficacy, with $\mathrm{AgNO}_{3}$ showing a high reaction yield.

AgNPs incorporation on the fabrics was effective. However, there was a substantial difference in AgNPs impregnations between cotton and polyester. The percentage of AgNPs incorporated on the cotton fabric was $2.7 \%, 2.7 \%$, and $12.5 \%$, with one, two, and four impregnations, respectively.

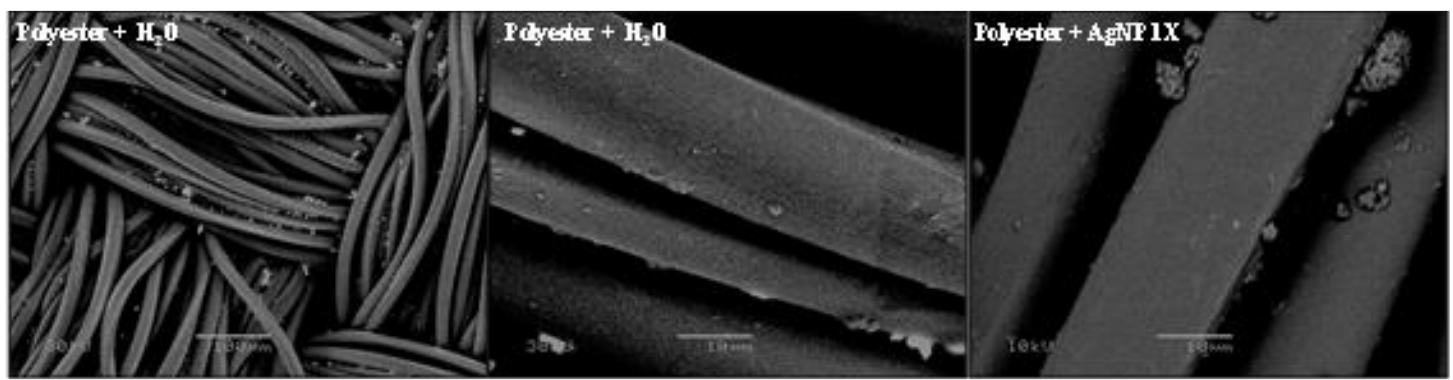

Figure 2. Scanning electron microscopy (SEM) images of the polyester fabrics without impregnation (polyester $\left.+\mathrm{H}_{2} \mathrm{O}\right)$ and impregnated with AgNPs by one and four times. Polyester $+\mathrm{H}_{2} \mathrm{O}(100$ and $10 \mu \mathrm{m})$; polyester $+\mathrm{AgNPs}$ $1 \mathrm{x}(10 \mu \mathrm{m})$.

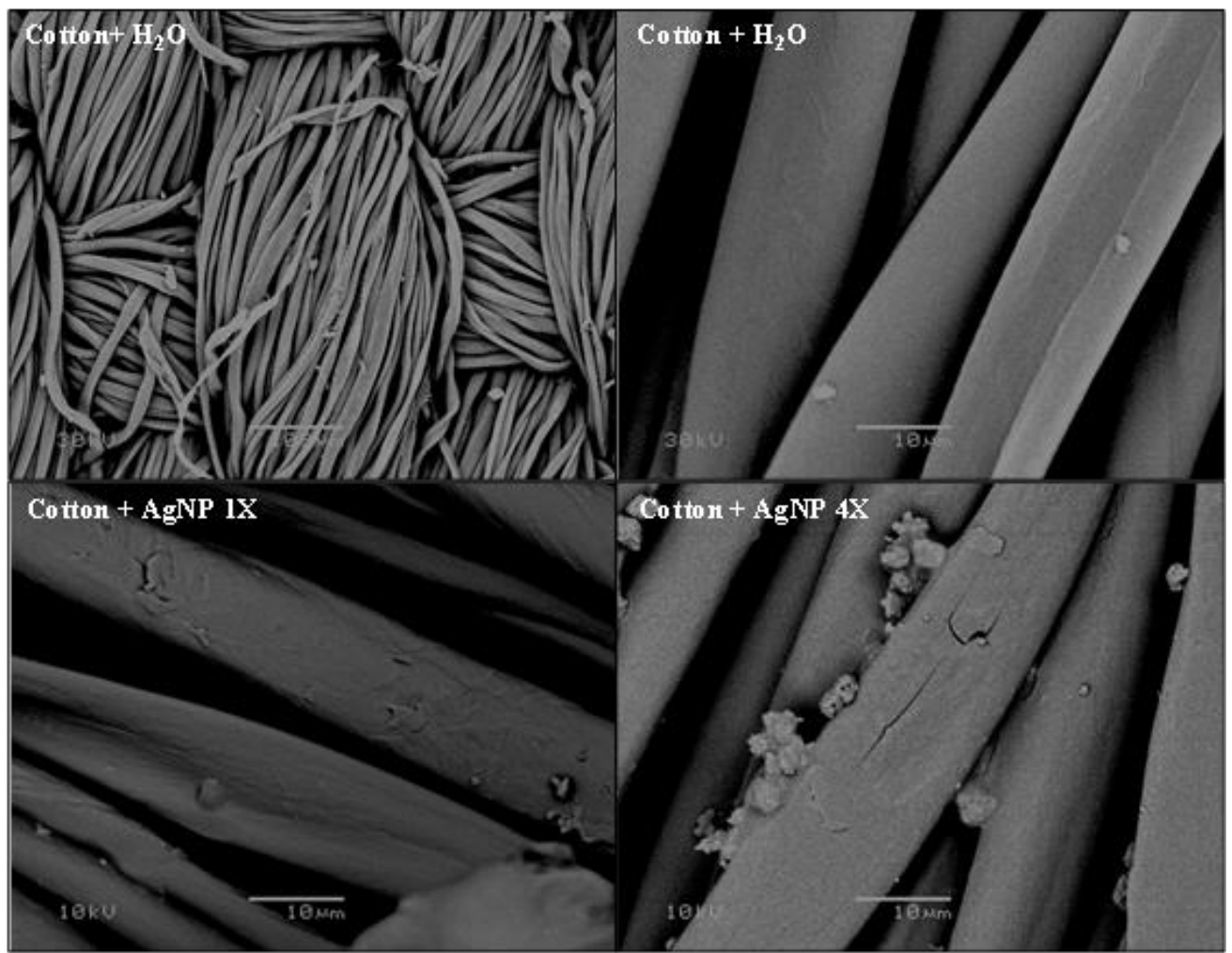

Figure 3. Scanning electron microscopy of the cotton fabrics without impregnation (cotton $\left.+\mathrm{H}_{2} \mathrm{O}\right)$ and impregnated with AgNPs by one and four times. Cotton $+\mathrm{H}_{2} \mathrm{O}(100$ and $10 \mu \mathrm{m})$; cotton $+\operatorname{AgNPs} 1 \mathrm{x}(10 \mu \mathrm{m})$; cotton + AgNPs 4x $(10 \mu \mathrm{m})$. 
For polyester fabric, the impregnation pointed out to uniform AgNPs incorporation reaching 9.9\%, 9.3\%, and 8.4\% when impregnated one, two, and four times, respectively. As can be observed, there was no significant variation among the repetitions.

Figures 2 and 3 represent the SEM of polyester and cotton fabrics before and after incorporating AgNPs. It is possible to observe the AgNPs on the surface of the fabrics. It can be seen that the amount of AgNPs adhered to the cotton fabric surface that suffered four impregnations, as expected, is higher than other impregnation procedures.

Most likely, there was a saturation of the polyester fabric after the first impregnation. This was not observed on cotton, in which the most efficient impregnation process was repeated four times. The AgNPs adhered on the fabric's surface, mainly for the cotton fabric impregnated four times, as observed by SEM. The profile of AgNPs incorporation in cotton fabric is similar to that obtained using biological AgNPs from Fusarium oxysporum [16].

\subsection{Antimicrobial activity of fabrics impregnated with AgNPs.}

Previously, the antimicrobial activity of biogenic AgNPs produced by A. tubingensis on Gram-negative and Gram-positive bacteria and on several species of clinical strains of Candida sp. was reported, and the nanoparticles showed high antibacterial and antifungal effect $[2]$.

In this study, both fabrics impregnated only once with AgNPs inhibited S. aureus and E. coli growth by $100 \%$.

C. albicans is usually present in infections caused by yeasts, and due to that, both fabrics, cotton and polyester, carrying the AgNPs were first tested on this yeast species. The cotton impregnated with AgNPs one, two, and four times inhibited the C. albicans by 80.1, 80.6 , and $83.5 \%$, respectively, while the polyester fabric effect was similar, inhibiting 86.3, 85.1 , and $76.2 \%$ of the yeast growth, respectively.

The antifungal effect of both fabrics carrying AgNPs impregnated one time was also observed on C. parapsilosis and C. glabrata, which were inhibited by 96.9 and $97.7 \%$, respectively. On $C$. albicans and $C$. parapisilosis, the polyester fabric was more effective than the cotton and inhibited the growth efficiently by $86.3 \%$ and $97.7 \%$. The inhibition induced by the cotton fabric carrying AgNPs on both yeasts was 80.1\% and 96.9. The cotton fabric carrying the AgNPs was more effective against $C$. glabrata and inhibited the growth by $97.9 \%$, whereas the polyester inhibition was $94.2 \%$.

Both fabrics showed remarkable antimicrobial effects against clinically relevant pathogens. Cotton fabric carrying AgNPs in different concentrations presented similar activities against $C$. albicans, and the fabric impregnated four times (12.5\% of AgNPs) showed slightly higher growth inhibition. The increase of 4.6 fold in the concentration of AgNPs from one to four impregnations was not relevant for improving the antifungal activity that increased only from 80.1 to $83.5 \%$. Likewise, polyester fabric with similar percentages of impregnated AgNPs also presented high growth inhibition for all impregnations. Thus, in both cases, only one impregnation of the fabrics with AgNPs was enough for achieving the nanoparticles' concentration and provided the significant antifungal effect of AgNPs textiles. Moreover, both fabrics carrying the AgNPs impregnated once efficiently inhibited $C$. parapsilosis and $C$. glabrata growth. The data shows that functionalized textiles were efficient in killing the pathogens, despite carrying AgNPs in low percentage.

The current data corroborate previous data from our laboratory, which show that cotton and polyester fabric carrying biological AgNPs obtained from the fungus Bionectria 
ochroleuca were very effective in inhibiting pathogenic yeasts and bacteria growth [9]. It is interesting to observe that the impregnation process by only one time is enough for obtaining fabrics carrying AgNPs in concentrations able to kill the yeasts. Besides, it is an advantage for future manufacturing. In a scale-up process, a small number of steps and a lower concentration of AgNPs for impregnation are advantageous to save both money and time, and the data presented here support this perspective.

\subsection{Anti-biofilm activity of AgNPs.}

The anti-biofilm activity of AgNPs was evaluated against $B$. subtilis exposed to AgNPs in concentrations between 0.01 to $50 \mu \mathrm{M}$ (Figure 4). AgNPs at $8 \mu \mathrm{M}$ inhibited the biofilm formation, but this effect did not increase when the bacteria were exposed to higher AgNPs concentration (Figure 5). $\mathrm{AgNO}_{3}$ inhibited biofilm formation in all assayed concentrations as well as the antibiotic streptomycin/penicillin $(2,500 \mathrm{UI} / \mathrm{mL} / 2.5 \mathrm{mg} / \mathrm{mL}$ - data not showed) used as control.

It is known that biofilm is a reservoir for pathogens in the hospital environment and medical devices and should be carefully and entirely eliminated. Functionalization of materials with AgNPs by coating or impregnation is a promising alternative to avoid microorganisms dissemination and biofilm formation [17].

B. subtilis is a Gram-positive bacterium usually found in the environment; however, it can cause diseases in humans like diarrhea and urinary tract infections, and even fatal infections [18]. Considering its relevance, in this study, the AgNPs were evaluated on B. subtilis and showed an anti-biofilm effect, also observed in the SEM results.

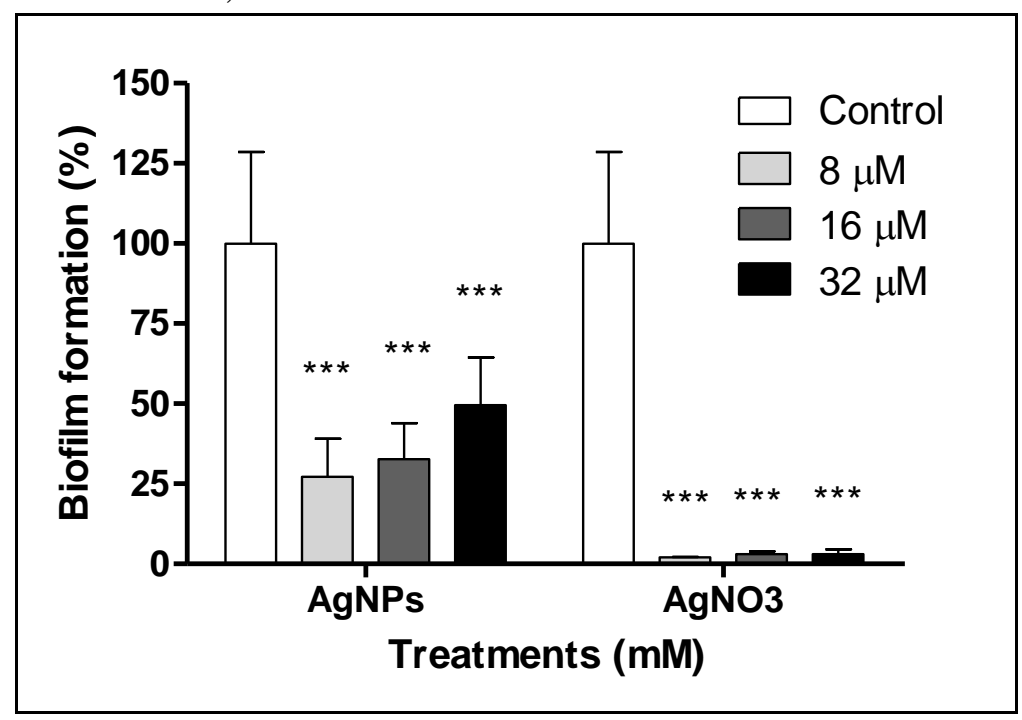

Figure 4. Biofilm formation for B. subtilis exposed to 8, 16 and $32 \mu \mathrm{M}$ of AgNPs obtained from A. tubingensis and $\mathrm{AgNO}_{3}$. Controls are only $B$. subtilis culture without treatment. Statistical analysis was performed using GraphPad Prism 5.0 software by two-way ANOVA / Bonferroni's multiple comparison tests. Differences in relation to the control values were considered statistically significant when $P<0.05$.

Literature data highlights the efficient antibacterial activity of AgNPs, even at low concentrations. AgNPs obtained from aqueous and ethanolic extract of Andrographis paniculata stem showed antibacterial effect on B. Subtilis [19], and that from exopolysaccharide of the bacterium Mesoflavibacter zeaxanthinifaciens also showed an antibiofilm effect on B. Subtilis [18]. 


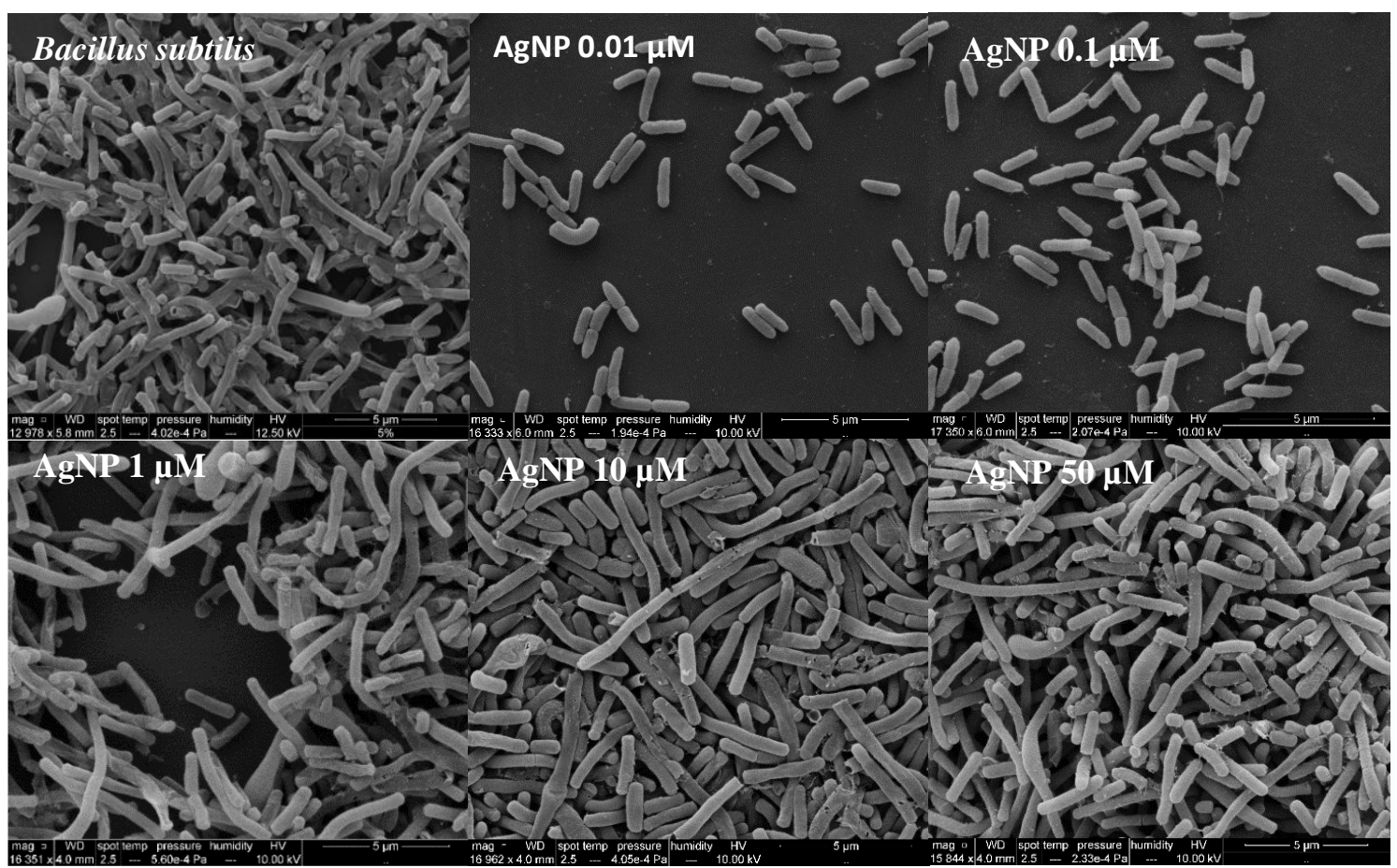

Figure 5. Scanning electron microscopy (SEM) for B. subtilis biofilm exposed to 0.01 until $50 \mu \mathrm{M}$ of AgNPs were obtained from $A$. tubingensis. Samples were covered with a gold film and examined with an FEI QUANTA $250 \mathrm{SEM}$ an accelerating voltage of $10 \mathrm{kV}$. Bars are at $5 \mu \mathrm{m}$.

The antimicrobial activity of nanoparticles is attributed to oxidative stress and the generation of reactive oxygen species (ROS) that cause disruption of microorganisms' membranes and their death [20]. Due to the small sizes, MNPs have a high surface area, and this property is advantageous for inhibiting biofilm formation, which promotes a direct interaction of nanoparticles and cell surfaces.

Biofilms are formed by the association of microorganisms able to maintain the communication and cooperation related to metabolism, gene expression, and virulence [21]. These mechanisms for survival have been adapted through the microorganisms' evolution, increasing their resistance to antimicrobial agents and protection from host defenses [22]. This interaction process among the cells can probably be modified by the presence of small nanoparticles that can penetrate the cells, interrupting communication and metabolism, inducing death as a result.

The biological AgNPs applied in this study have a size of $35 \pm 10 \mathrm{~nm}$ (TEM) and positive zeta potential on their surface $(+7.8)$ [2]. These properties are interesting to promote the interaction with bacterium cells. Although AgNPs showed an excellent antimicrobial activity and inhibited the biofilm formation at lower concentrations, unexpectedly, biofilm formation was not inhibited at higher concentrations. This result was observed in both analyses, and one hypothesis is that at higher concentrations, saturation and/or aggregation of the AgNPs may have occurred, which could not inhibit the cells' interactions, leading to biofilm formation. It is established that biofilms develop the extracellular matrix (ECM), which has a protective function in limiting the access of antimicrobial agents by physical contact or reducing the penetration rate and consequently the effectivity [23]. This is a reasonable explanation for the phenomenon observed here.

An extracellular polymeric substance such as nucleic acids, proteins, lipopeptides, and poly-gamma-glutamate (PGA) can be secreted by B. subtilis [24] and due to their tertiary structure and chemical properties, some of these compounds can react with metals. They can 
be applied for bioremediation of contaminated soils [25]. Eymard-Vernain et al. [26] showed that synthetic AgNPs surrounded by polyvinylpyrrolidone (PVP) presented no significant effect on the intracellular physiology of $B$. subtilis during the stationary phase and that the secreted bioorganic molecules - PGA - interacted with the AgNPs. PGA may physically interact with the AgNPs by trapping them, thereby decreasing their bioavailability and, consequently, the biocidal effect [26]. It may have occurred when the B. subtilis tested herein was exposed to higher concentrations of AgNPs. Perhaps the most stressful condition had stimulated a higher PGA production (or any other specific proteins to resist environmental stresses), neutralizing the AgNP effect, allowing the bacterial growth, as observed when the bacteria were exposed to increasing concentrations of AgNP.

The effect of AgNPs on the biofilm observed in this study agrees with previous data showing that bacteria from mature bacterial biofilm [27, 28] or stationary phase [24] are more resistant to AgNPs. Although no doubt exists about the biological AgNPs anti-biofilm effect at low concentrations, additional studies are necessary to understand its interaction with $B$. subtilis biofilm in different concentrations.

\section{Conclusions}

This research showed that the impregnation of cotton and polyester fabrics with AgNP was very efficient, and both fabrics showed strong antimicrobial effects against clinically relevant pathogens and excellent antimicrobial activity of the free AgNPs against such pathogens.

Further research could be useful to determine the threshold of the inhibition of the microorganisms' growth by AgNPs, its use even at lower concentrations on fabrics, and better understand the process of antimicrobial and anti-biofilm effect.

It can be anticipated that the applications of functionalized textiles containing AgNPs will play a key role in the near future in combating pathogenic strains, thereby offering an alternative to design effective solutions against hospital-acquired nosocomial infections.

\section{Funding}

This work was supported by the Fundação de Amparo à Pesquisa do Estado de São Paulo (FAPESP, Grant number: 2010/50186-5) and Coordenação de Aperfeiçoamento de Pessoal de Nível Superior (CAPES).

\section{Acknowledgments}

Authors thank the scanning electron microscopy facilities from the Butantan Institute for technical support.

\section{Conflicts of Interest}

The authors declare no conflict of interest.

\section{References}

1. Henriksen, T.-H.; Abebe, W.; Amogne, W.; Getachew, Y.; Weedon-Fekjær, H.; Klein, J.; Woldeamanuel, Y. Association between antimicrobial resistance among Enterobacteriaceae and burden of environmental bacteria in hospital acquired infections: analysis of clinical studies and national reports. Heliyon 2019, 5 , e02054, https://doi.org/10.1016/j.heliyon.2019.e02054. 
2. Rodrigues, A.G.; Ping, L.Y.; Marcato, P.D.; Alves, O.L.; Silva, M.C.P.; Ruiz, R.C.; Melo, I.S.; Tasic, L.; De Souza, A.O. Biogenic antimicrobial silver nanoparticles produced by fungi. Appl. Microbiol. Biotechnol. 2013, 97, 775-782, https://doi.org/10.1007/s00253-012-4209-7.

3. Namasivayam, S.K.R.; Shyamsundar, D.; Prabanch, M.M.; Bharani, R.S.A.; Avinash, G.P. Inhibitory potential of molecular mechanism of pathogenesis with special reference to biofilm inhibition by chemogenic zinc oxide nanoparticles. Lett Appl Bionanoscience 2021, 10, 1862-1870, https://doi.org/10.33263/LIANBS101.18621870.

4. Wang, S.; Gao, Y.; Jin, Q.; Ji, J. Emerging antibacterial nanomedicine for enhanced antibiotic therapy. Biomater. Sci. 2020, 8, 6825-6839, https://doi.org/10.1039/d0bm00974a.

5. Anugrahwidya, R.; Yudasari, N.; Tahir, D. Optical and structural investigation of synthesis $\mathrm{ZnO} / \mathrm{Ag}$ Nanoparticles prepared by laser ablation in liquid. Mater. Sci. Semicond. Process. 2020, 105, 104712, https://doi.org/10.1016/j.mssp.2019.104712.

6. Nguyen, T.H.N.; Nguyen, T.D.; Cao, M.T.; Pham, V.V. Fast and simple synthesis of triangular silver nanoparticles under the assistance of light. Colloids Surf. Physicochem. Eng. Aspects 2020, 594, 124659, https://doi.org/10.1016/j.colsurfa.2020.124659.

7. Qu, Y.; Pei, X.; Shen, W.; Zhang, X.; Wang, J.; Zhang, Z.; Li, S.; You, S.; Ma, F.; Zhou, J. Biosynthesis of gold nanoparticles by Aspergillum sp. WL-Au for degradation of aromatic pollutants. Physica E: Lowd Dimens. Syst. Nanostruct. 2017, 88, 133-141, https://doi.org/10.1016/j.physe.2017.01.010.

8. Hashemi, S.F.; Tasharrofi, N.; Saber, M.M. Green synthesis of silver nanoparticles using Teucrium polium leaf extract and assessment of their antitumor effects against MNK45 human gastric cancer cell line. J. Mol. Struct. 2020, 1208, 127889, https://doi.org/10.1016/j.molstruc.2020.127889.

9. Rodrigues, A.G.; Gonçalves, P.J.R.O.; Ottoni, C.A.; de Cássia Ruiz, R.; Morgano, M.A.; de Araújo, W.L.; de Melo, I.S.; De Souza, A.O. Functional textiles impregnated with biogenic silver nanoparticles from Bionectria ochroleuca and its antimicrobial activity. Biomed. Microdevices 2019, 21, 56, https://doi.org/10.1007/s10544-019-0410-0.

10. Cerimi, K.; Akkaya, K.C.; Pohl, C.; Schmidt, B.; Neubauer, P. Fungi as source for new bio-based materials: a patent review. Fungal Biology and Biotechnology 2019, 6, 17, https://doi.org/10.1186/s40694-019-0080-y.

11. Kitching, M.; Ramani, M.; Marsili, E. Fungal biosynthesis of gold nanoparticles: mechanism and scale up. Microb. Biotechnol. 2015, 8, 904-917, https://doi.org/10.1111/1751-7915.12151.

12. Araújo, W.L.; Maccheroni Jr, W.; Aguilar-Vildoso, C.I.; Barroso, P.A.V.; Saridakis, H.O.; Azevedo, J.L. Variability and interactions between endophytic bacteria and fungi isolated from leaf tissues of citrus rootstocks. Can. J. Microbiol. 2001, 47, 229-236, https://doi.org/10.1139/w00-146.

13. Morris, J.K. A formaldehyde glutaraldehyde fixative of high osmolality for use in electron microscopy. $J$. cell Biol 1965, 27, 1A-149A.

14. Heymann, J.A.W.; Hayles, M.; Gestmann, I.; Giannuzzi, L.A.; Lich, B.; Subramaniam, S. Site-specific 3D imaging of cells and tissues with a dual beam microscope. J. Struct. Biol. 2006, 155, 63-73, https://doi:10.1016/j.jsb.2006.03.006.

15. Zulkifli, N.A.; Zakaria, L. Morphological and molecular diversity of Aspergillus from corn grain used as livestock feed. Hayati J. Biosciences 2017, 24, 26-34, https://doi.org/10.1016/j.hjb.2017.05.002.

16. Durán, N.; Marcato, P.D.; De Souza, G.I.H.; Alves, O.L.; Esposito, E. Antibacterial effect of silver nanoparticles produced by fungal process on textile fabrics and their effluent treatment. J. Biomed. Nanotechnol. 2007, 3, 203-208, https://doi.org/10.1166/jbn.2007.022.

17. Leau, S.A.; Marin, S.; Coara, G.; Albu, L.; Constantinescu, R.R.; Kaya, M.A.; Neacsu, I.A. Study of wound-dressing materials based on collagen, sodium carboxymethylcellulose and silver nanoparticles used for their antibacterial activity in burn injuries. Proceedings of the $7^{\text {th }}$ International Conference on Advanced Materials and Systems, pp. 123-128, 2018, doi: 10.24264/icams-2018.I.18, WOS:000464905000018.

18. Oves, M.; Rauf, M.A.; Hussain, A.; Qari, H.A.; Khan, A.A.P.; Muhammad, P.; Rehman, M.T.; Alajmi, M.F.; Ismail, I.I.M. Antibacterial Silver nanomaterial synthesis from Mesoflavibacter zeaxanthinifaciens and targeting biofilm formation. Front. Pharmacol. 2019, 10, 801, https://doi.org/10.3389/fphar.2019.00801.

19. Hossain, M.M.; Polash, S.A.; Takikawa, M.; Shubhra, R.D.; Saha, T.; Islam, Z.; Hossain, S.; Hasan, M.A.; Takeoka, S.; Sarker, S.R. Investigation of the antibacterial activity and in vivo cytotoxicity of biogenic silver nanoparticles as potent therapeutics. Front. Bioeng. Biotechnol. 2019, 7, 239, https://doi.org/10.3389/fbioe.2019.00239. 
20. Dobrucka, R.; Dlugaszewska, J.; Kaczmarek, M. Cytotoxic and antimicrobial effects of biosynthesized ZnO nanoparticles using of Chelidonium majus extract. Biomed. Microdevices 2017, 20, 5, https://doi.org/10.1007/s10544-017-0233-9.

21. Percival, S.L.; Emanuel, C.; Cutting, K.F.; Williams, D.W. Microbiology of the skin and the role of biofilms in infection. Int. Wound J. 2012, 9, 14-32, https://doi.org/10.1111/j.1742-481X.2011.00836.x.

22. Ramage, G.; Mowat, E.; Jones, B.; Williams, C.; Lopez-Ribot, J. Our current understanding of fungal biofilms. Crit. Rev. Microbiol. 2009, 35, 340-355, https://doi.org/10.3109/10408410903241436.

23. Costerton, J.W.; Stewart, P.S.; Greenberg, E.P. Bacterial biofilms: A common cause of persistent infections. Science 1999, 284, 1318, https://doi.org/10.1126/science.284.5418.1318.

24. Marvasi, M.; Visscher, P.T.; Casillas Martinez, L. Exopolymeric substances (EPS) from Bacillus subtilis: polymers and genes encoding their synthesis. FEMS Microbiol. Lett. 2010, 313, 1-9, https://doi.org/10.1111/j.1574-6968.2010.02085.x.

25. Hakumai, Y.; Oike, S.; Shibata, Y.; Ashiuchi, M. Cooperative adsorption of critical metal ions using archaeal poly- $\gamma$-glutamate. BioMetals 2016, 29, 527-534, https://doi.org/10.1007/s10534-016-9928-2.

26. Eymard-Vernain, E.; Coute, Y.; Adrait, A.; Rabilloud, T.; Sarret, G.; Lelong, C. The poly-gamma-glutamate of Bacillus subtilis interacts specifically with silver nanoparticles. PLoS One 2018, 13, e0197501, https://dx.doi.org/10.1371/journal.pone.0197501.

27. $\mathrm{Yu}, \mathrm{D}$.-G. Formation of colloidal silver nanoparticles stabilized by $\mathrm{Na}^{+}-$poly $(\gamma$-glutamic acid)-silver nitrate complex via chemical reduction process. Colloids Surf. B. Biointerfaces 2007, 59, 171-178, https://doi.org/10.1016/j.colsurfb.2007.05.007.

28. Sheng, Z.; Liu, Y. Potential impacts of silver nanoparticles on bacteria in the aquatic environment. J. Environ. Manage. 2017, 191, 290-296, https://doi.org/10.1016/j.jenvman.2017.01.028. 